\title{
Pre-Hospital Antiplatelet Therapy for STEMI Patients Undergoing Primary Percutaneous Coronary Intervention: What We Know and What Lies Ahead
}

\author{
Enrico Fabris ${ }^{10}$ Serge Korjian ${ }^{2}$ Barry S. Coller ${ }^{3}$ \\ C. Michael Gibson'² Arnoud W. J. van 't Hof ${ }^{6,7,8}$ \\ ${ }^{1}$ Cardiovascular Department, University of Trieste, Trieste, Italy \\ ${ }^{2}$ Beth Israel Deaconess Medical Center, Harvard Medical School, \\ Boston, Massachusetts, United States \\ ${ }^{3}$ Allen and Frances Adler Laboratory of Blood and Vascular Biology, \\ Rockefeller University, New York, New York, United States \\ ${ }^{4}$ Department of Cardiology, St Antonius Hospital, Nieuwegein, \\ The Netherlands \\ ${ }^{5}$ Duke Clinical Research Institute and the Division of Cardiology, Duke \\ University Medical Center, Durham, North Carolina, United States \\ ${ }^{6}$ Department of Cardiology, Zuyderland Medical Centre, Heerlen, \\ The Netherlands \\ ${ }^{7}$ Department of Cardiology, Maastricht University Medical Centre, \\ Maastricht, The Netherlands \\ ${ }^{8}$ Cardiovascular Research Institute Maastricht (CARIM), Maastricht, \\ The Netherlands
}

Thromb Haemost 2021;121:1562-1573.
Jurrien M. Ten Berg ${ }^{4}$ Christopher B. Granger ${ }^{5}$

Address for correspondence Arnoud W. J. van 't Hof, MD, PhD, Department of Interventional Cardiology in Maastricht University Medical Center and Zuyderland Medical Center in Heerlen, P. Debyelaan 25, 6229 HX Maastricht, MUMC+, Level 3, Postbus 5800, 6202 AZ Maastricht, The Netherlands (e-mail: arnoud.vant.hof@mumc.nl).

\author{
Abstract \\ Keywords \\ - myocardial infarction \\ - STEMI \\ - pre-hospital \\ - coronary reperfusion \\ - antiplatelet therapy \\ - P2Y 12 inhibitors \\ - glycoprotein IIb/IIla \\ - selatogrel \\ - RUC-4
}

Early recanalization of the infarct-related artery to achieve myocardial reperfusion is the primary therapeutic goal in patients with ST-elevation myocardial infarction (STEMI). To decrease the duration of ischaemia, continuous efforts have been made to improve pre-hospital treatment and to target the early period after symptom onset. In this period the platelet content of the fresh coronary thrombus is maximal and the thrombi are dynamic, and thus more susceptible to powerful antiplatelet agents. There have been substantial advances in antiplatelet therapy in the last three decades with several classes of oral and intravenous antiplatelet agents with different therapeutic targets, pharmacokinetics, and pharmacodynamic properties. New parenteral drugs achieve immediate inhibition of platelet aggregation, and fast and easy methods of administration may create the opportunity to bridge the initial gap in platelet inhibition

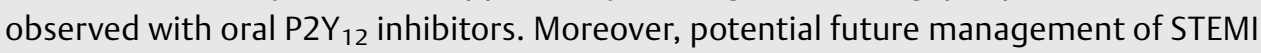
could directly involve patients in the process of care with self-administered antiplatelet agents designed to achieve rapid reperfusion. However, the potential anti-ischaemic benefits of potent antiplatelet agents will need to be balanced against their risk of increased bleeding. This study presents a comprehensive and updated review of prehospital antiplatelet therapy among STEMI patients undergoing primary percutaneous intervention and explores new therapies under development. received

December 22, 2020

accepted after revision

March 2, 2021

published online

March 7, 2021 (c) 2021. Thieme. All rights reserved. Georg Thieme Verlag KG,

Rüdigerstraße 14,

70469 Stuttgart, Germany
DOI https://doi.org/

10.1055/a-1414-5009.

ISSN 0340-6245. 


\section{Introduction}

ST-elevation myocardial infarction (STEMI) is characterized by a tear or erosion of an atherosclerotic plaque in the coronary circulation, followed by occlusive or near-occlusive arterial thrombus formation and critical reduction in blood flow to the downstream myocardial tissue. ${ }^{1}$ Although rare, coronary artery thromboembolism is a non-atherosclerotic cause of STEMI, and may be a clinical manifestation of a hypercoagulable state. ${ }^{2}$

Early and complete recanalization of the infarct-related artery to achieve myocardial reperfusion significantly reduces morbidity and mortality among patients with STEMI and is the primary therapeutic goal. ${ }^{3}$ Current practice guidelines emphasize the organization of STEMI networks since they decrease transfer time to primary percutaneous coronary intervention (PCI) centres and allow the initiation of STEMI treatment at the first medical contact by trained and equipped medical or paramedical staff. ${ }^{3}$ Indeed there is a general consensus that early administration of antiplatelet therapy should be given early when the probability of $\mathrm{PCI}$ is high such as for STEMI. ${ }^{4}$

There have been substantial advances in antiplatelet therapy in the last three decades, with several classes of oral and intravenous (IV) antiplatelet agents with different therapeutic targets, pharmacokinetics and pharmacodynamic properties. Nevertheless, finding the optimal therapeutic regimen and the appropriate timing of drug administration remains a clinical challenge. In an effort to decrease the duration of ischaemia, the early period after symptom onset represents a golden opportunity in the management of STEMI patients. Accordingly, continuous efforts have been made to improve pre-hospital treatment to target this critical time period. This study presents a comprehensive and updated review of pre-hospital antiplatelet therapy among STEMI patients undergoing primary PCI and explores new therapies under development.

\section{Platelet Inhibition}

STEMI is a dynamic event in which platelet activation is a key step in the process leading up to thrombus formation. ${ }^{5}$ Disruption of the cap of an atherosclerotic plaque exposes matrix proteins to which platelets adhere, leading to platelet activation and release of the platelet activators thromboxane A2 and adenosine diphosphate (ADP). ${ }^{6}$ These mediators amplify the initial platelet response by binding to their cognate platelet receptors, including the binding of ADP to the platelet $\mathrm{P}_{2} \mathrm{Y}_{1}$ and $\mathrm{P}_{2} \mathrm{Y}_{12}$ receptors, ${ }^{7}$ resulting in a conformational change of the $\alpha$ IIb $\beta 3$ (glycoprotein IIb/IIla [GPIIb/IIIa]) receptors on platelets, binding of the plasma proteins fibrinogen and von Willebrand factor ( $\mathrm{vWF}$ ), and platelet aggregation, ${ }^{8}$ which creates the nucleus for further thrombus formation. This mechanism occurs rapidly and progressively, thus supporting the need for pharmacotherapies that are fast acting and easily administered. Thus, instituting antithrombotic therapy in the early period after symptom onset provides the best opportunity for improving the outcome of STEMI. ${ }^{9,10}$
Early platelet inhibition facilitates epicardial reperfusion, reduces thrombotic burden, improves microcirculatory function, and reduces ischaemic complications such as stent thrombosis (ST). ${ }^{11-14} \mathrm{~A}$ rapid onset of action (especially in STEMI setting where both the duration of the period of platelet-rich dynamic thrombus formation and the reperfusion benefit are time dependent) and more effective platelet inhibition seem key elements in improving thrombotic outcomes. It has been shown that patients with the highest inhibition of platelet aggregation have less residual STsegment deviation 1 hour post-PCI. ${ }^{15}$ Moreover, there is a significant relationship between platelet function and major adverse cardiovascular events (MACE) and early thrombosis. ${ }^{15}$ Data from GPI dosing demonstrate a relationship between achieving at least $80 \%$ inhibition of ADP-induced platelet aggregation and clinical outcomes. ${ }^{16}$ However, more potent platelet inhibition is associated with increased risk of bleeding. Thus, the risk-to-benefit ratio needs to be personalized to the individual patient's risk of morbidity and mortality related to thrombosis versus their risk of bleeding, especially in elderly patients. ${ }^{17}$ However, upstream antiplatelet treatment in STEMI patients has been shown to be relatively safe in terms of major bleeding events. ${ }^{18-20}$

Different classes of antiplatelet drugs are currently available, including oral cyclooxygenase-1 (COX-1) inhibitors (aspirin), $\mathrm{P}_{2} \mathrm{Y}_{12}$ receptor inhibitors (the oral thienopyridines clopidogrel and prasugrel, the cyclopentyl-triazolopyrimidine ticagrelor, and the IV adenosine triphosphate [ATP] analogue cangrelor), and IV GPIIb/IIIa receptor inhibitors (GPIs; abciximab, tirofiban, eptifibatide). Furthermore, novel agents under investigation include a selective antagonist of the $\mathrm{P}_{2} \mathrm{Y}_{12}$ receptor developed for subcutaneous administration (Selatogrel) as well as a subcutaneous GPIIb/IIIa receptor inhibitor (RUC-4; - Fig. 1; - Table 1).

\section{Oral Agents}

\section{Aspirin}

Aspirin is the oldest antiplatelet drug. Aspirin functions primarily by inhibiting production of thromboxane A2 by the enzyme COX-1. ${ }^{21}$ The ISIS-2 (Second International Study of Infarct Survival) study was the first trial to demonstrate the efficacy and safety of aspirin following acute myocardial infarction (AMI). The study showed a significant reduction in vascular death among patients who received aspirin compared with placebo (odds reduction: $23 \pm 4 \%$; $p<0.00001$ ), and aspirin was also associated with significant reductions in re-infarction ( 1.0 vs. $2.0 \%$ ) and stroke ( 0.3 vs. $0.6 \%) .{ }^{22}$ Subsequently, aspirin became the mainstay of AMI treatment, administered as early as possible in all patients with minimal contraindications. Aspirin can be administered orally, and is available in several formulations; non-enteric-coated aspirin and chewed aspirin tablets are recommended in the setting of AMI. ${ }^{3}$ Despite the lack of clinical data on the differences among formulations, liquid formulation results in higher peak plasma levels at an earlier time point after administration. $^{23}$ Slightly different oral loading doses are recommended depending on the region: 150 to $300 \mathrm{mg}$ in 


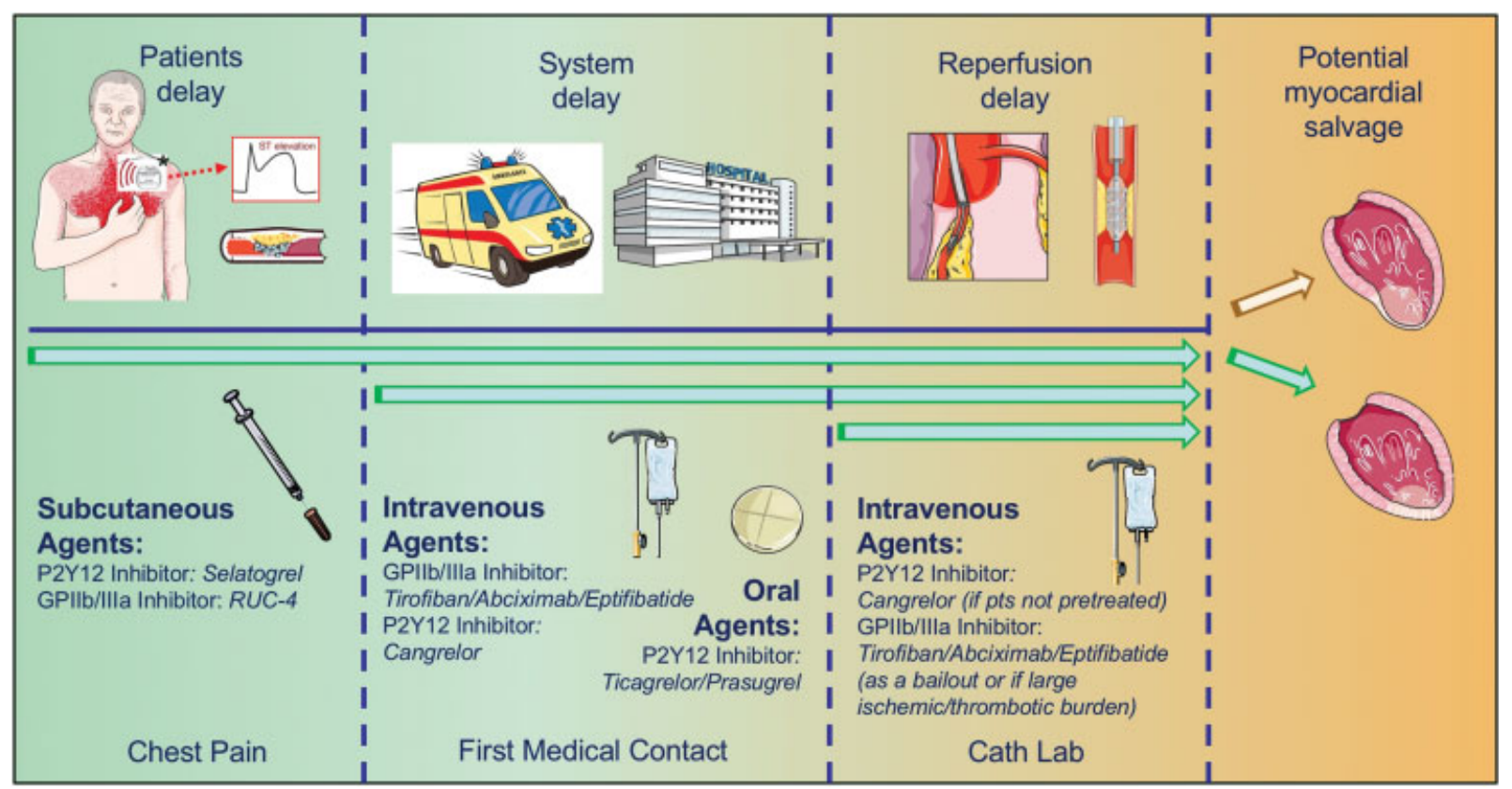

Fig. 1 Different antiplatelet drugs and potential timing of administration before PCI (Pts, patients; GPIIb/IIla, glycoprotein IIb/IIla; *implantable or wearable devices, may provide timely recognition of ST elevation, i.e., diagnosis of STEMI could not require the arrival of the ambulance).

Europe $^{3}$ and 162 to $325 \mathrm{mg}$ in the United States. ${ }^{24}$ IV administration is also feasible and European guidelines recommend the dosage of 75 to $250 \mathrm{mg} \mathrm{IV},{ }^{3}$ but there are limited data on the optimal IV dosage. A single loading dose of 250 or $500 \mathrm{mg}$ of IV compared with $300 \mathrm{mg}$ of oral aspirin was associated with faster and more complete inhibition of thromboxane generation and platelet aggregation in a small clinical study, with no differences in bleeding complica- tions. ${ }^{25}$ Nevertheless, it is unclear if IV administration of aspirin results in improved clinical outcomes.

\section{Oral $\mathrm{P}_{2} \mathrm{Y}_{12}$ Receptor Inhibitors}

$\mathrm{P} \mathrm{Y}_{12}$ receptor inhibitors diminish platelet activation induced by ADP. ${ }^{26}$ There is a large body of data that support a dual antiplatelet therapy (DAPT), that is, aspirin plus a $\mathrm{P} \mathrm{Y}_{12}$ inhibitor, in patients with acute coronary syndrome

Table 1 Major characteristics of traditional and newer antiplatelet drugs

\begin{tabular}{|c|c|c|c|c|c|c|c|}
\hline Antiplatelet agent & Mechanism of action & Reversibility & Onset of action & Peak effect & $\begin{array}{l}\text { Duration } \\
\text { of action }\end{array}$ & $\begin{array}{l}\text { Route of } \\
\text { administration }\end{array}$ & $\begin{array}{l}\text { Trials of prehospital } \\
\text { administration }\end{array}$ \\
\hline Aspirin & $\begin{array}{l}\text { Acetylation of platelet } \\
\text { cyclooxygenase }\end{array}$ & Irreversible & $30-60 \min$ & $1-2 \mathrm{~h}$ & $10 \mathrm{~d}$ & PO, IV, PR & - \\
\hline \multicolumn{8}{|l|}{$P 2 Y_{12}$ inhibitors } \\
\hline Clopidogrel & \multirow{5}{*}{$\begin{array}{l}\text { Binding to the } P 2 Y_{12} \\
\text { component of } A D P \\
\text { receptors }\end{array}$} & Irreversible & $2 \mathrm{~h}$ & $6 \mathrm{~h}$ & $5 d$ & $\mathrm{PO}$ & $\begin{array}{l}\text { Zeymer et al }{ }^{47} \text {; } \\
\text { Ducci et al }{ }^{46}\end{array}$ \\
\hline Prasugrel & & Irreversible & $<30$ min & $4 \mathrm{~h}$ & $5-9 d$ & $\mathrm{PO}$ & Vlachojannis et a ${ }^{56}$ \\
\hline Ticagrelor & & Reversible & $30 \mathrm{~min}$ & $2 \mathrm{~h}$ & $3 d$ & $\mathrm{PO}$ & Montalescot et $\mathrm{al}^{19}$ \\
\hline Cangrelor & & Reversible & $2 \mathrm{~min}$ & $30 \mathrm{~min}$ & $1 \mathrm{~h}$ & IV & - \\
\hline Selatogrel & & Reversible & $15 \mathrm{~min}$ & $30-60 \mathrm{~min}^{\ddagger}$ & $4-12 \mathrm{~h}$ & SC & In planning \\
\hline \multicolumn{8}{|c|}{ Glycoprotein IIb/IIIa inhibitors } \\
\hline Abciximab & \multirow[t]{4}{*}{$\begin{array}{l}\text { Binding to glycoprotein } \\
\text { Ilb/IIla receptors }\end{array}$} & Irreversible & $<10 \min$ & $30 \mathrm{~min}$ & $3-5 h^{a}$ & IV & $\begin{array}{l}\text { Montalescot et al } \\
\text { Arntz et al }\end{array}$ \\
\hline Eptifibatide & & Reversible & $<5 \mathrm{~min}$ & $1 \mathrm{~h}$ & $4-8 \mathrm{~h}$ & IV & Hanefeld et $\mathrm{al}^{73}$ \\
\hline Tirofiban & & Reversible & $<10 \min$ & $30 \mathrm{~min}$ & $4-8 \mathrm{~h}$ & IV & van't Hof et al ${ }^{18}$ \\
\hline RUC-4 & & Reversible $^{\mathrm{b}}$ & $<15$ min & $30-60 \mathrm{~min}$ & $2-4 h^{c}$ & SC & $\begin{array}{l}\text { Ongoing } \\
\text { (NCT04284995) }\end{array}$ \\
\hline
\end{tabular}

Abbreviations: ADP, adenosine diphosphate; IV, intravenous; PO, per os; PR, per rectum; SC, subcutaneous.

aplatelet bound antibody detected in the circulation up to 15 days after administration.

${ }^{b}$ Although conformational change to receptor is irreversible, drug effects are reversible.

'Dose dependent. 
(ACS) ${ }^{27}$ Clopidogrel, prasugrel, and ticagrelor are the three widely available oral $\mathrm{P}^{2} \mathrm{Y}_{12}$ inhibitors. Compared with clopidogrel, prasugrel and ticagrelor exhibit a faster onset of action, as well as more profound and consistent platelet inhibition. The landmark trials of prasugrel and ticagrelor, the TRITON TIMI 38 (Trial to Assess Improvement in Therapeutic Outcomes by Optimizing Platelet Inhibition with Prasugrel-Thrombolysis in Myocardial Infarction) $)^{28}$ and PLATO trials (Study of Platelet Inhibition and Patient Outcomes), ${ }^{29}$ respectively, showed superior efficacy of these agents compared with clopidogrel, but at the expense of an increase in major bleeding. Recommendations have relegated the use of clopidogrel to patients who have contraindications to prasugrel and ticagrelor, and patients receiving oral anticoagulants. ${ }^{3}$ Nevertheless, clopidogrel remains one of the primary oral $\mathrm{P}_{2} \mathrm{Y}_{12}$ agents employed in real-world practice. ${ }^{29}$ Moreover, using a CYP2C19 genotypeguided strategy, clopidogrel may be non-inferior to standard treatment with prasugrel or ticagrelor. ${ }^{30}$

In a comparison of prasugrel vs. ticagrelor, the RAPID trial found no difference in terms of residual platelet reactivity 2 hours after the loading dose in STEMI patients. ${ }^{31}$ The PRAGUE-18 study, which enrolled 90\% STEMI patients and was stopped early for futility, showed no significant difference in the rate of the primary end point of death, reinfarction, urgent target vessel revascularization, stroke, or serious bleeding at 30 days between hospital arrival administration of prasugrel and ticagrelor in ACS patients. ${ }^{32}$ In the 1,653 STEMI patient subgroup of the ISAR-REACT 5 trial, ${ }^{33}$ there was no significant difference in the primary composite end point (death, myocardial infarction [MI], or stroke) at 1 year after in-hospital randomization between prasugrel and ticagrelor. ${ }^{34}$ With the limit of the open-label design and telephone follow-up in more than $90 \%$ of patients, ticagrelor was associated with higher risk of recurrent MI. ${ }^{34}$ More data are needed to evaluate the difference between prasugrel and ticagrelor in STEMI patients. Moreover, in this study, STEMI patients were randomized in the hospital phase of treatment; indeed, the randomization took place as soon as possible after admission, ${ }^{35}$ and this prevented the initiation of anti-aggregation therapy in the ambulance.

The recommended loading dose of clopidogrel is $600 \mathrm{mg}$ orally, followed by a maintenance dose of $75 \mathrm{mg} / \mathrm{d}$; for ticagrelor, the loading dose is $180 \mathrm{mg}$ orally, followed by $90 \mathrm{mg}$ twice a day; and for prasugrel, the loading dose is $60 \mathrm{mg}$ orally, followed by $10 \mathrm{mg} / \mathrm{d}$; however, for patients with body weight $\leq 60 \mathrm{~kg}$, a maintenance dose of $5 \mathrm{mg} / \mathrm{d}$ is recommended. In patients $\geq 75$ years of age, prasugrel is generally not recommended, but a dose of $5 \mathrm{mg} / \mathrm{d}$ is acceptable if treatment is deemed necessary. Prasugrel is contraindicated in patients with previous stroke or transient ischaemic attack. ${ }^{3}$ In selected population, such as elderly or low-weight patients, a reduced dose of prasugrel, compared with the standard dose of ticagrelor, is associated with maintained anti-ischaemic efficacy while protecting these patients against the excess risk of bleeding during 12 months of follow-up. ${ }^{36}$

The optimal timing of DAPT is still subject to debate. Administration of antiplatelet agents at initial contact (in the ambulance or at the emergency department) leads to earlier onset of desired antiplatelet effects, and theoretically, this should translate into improved outcomes. Early administration of oral antiplatelet agents in STEMI patients is complicated by the potential for diminished drug absorption by unfavourable haemodynamic conditions and drug-drug interactions (e.g., with morphine ${ }^{37}$ ). Morphine delays clopidogrel absorption, decreases plasma levels of clopidogrel active metabolite, and retards and diminishes its effects. ${ }^{38}$ In STEMI patients, morphine use was associated with a delayed onset of action of both prasugrel and ticagrelor (and without difference between the two drugs) even after adjusting for the propensity to receive morphine and after excluding patients who suffered regurgitation. ${ }^{39}$ The U.S. Food and Drug Administration (FDA) recommends consideration of a parenteral antiplatelet agent in ACS patients requiring coadministration of morphine or other opioid agonists because of the opioids' impact on the absorption of oral $\mathrm{P}_{2} \mathrm{Y}_{12}$ antagonists. In a recent study, a routine GPI use in morphine-treated STEMI patients undergoing primary $\mathrm{PCI}$ appeared to protect against ST. ${ }^{40}$

In observational registries ${ }^{41-44}$ and a meta-analysis, ${ }^{45}$ clopidogrel pre-treatment has been significantly associated with a reduction in major coronary events and death; however, two small randomized studies ${ }^{46,47}$ did not show significant improvement with clopidogrel pre-treatment in terms of myocardial reperfusion. Despite the rationale that supports early administration of oral $\mathrm{P}_{2} \mathrm{Y}_{12}$ inhibitors, ticagrelor is the only $\mathrm{P}_{2} \mathrm{Y}_{12}$ inhibitor to have been evaluated in a prospective and randomized fashion in the ATLANTIC trial (Administration of Ticagrelor in the Cath Laboratory or in the Ambulance for New ST Elevation Myocardial Infarction to Open the Coronary Artery). Pre-hospital administration of ticagrelor was safe and was not associated with increased bleeding; however, platelet function testing demonstrated that it produced little antiplatelet effect in the pre-hospital phase. ${ }^{19}$ There was no significant difference between the pre- and in-hospital treatment groups in terms of ST-segment elevation resolution and TIMI flow grade 3 at the time of admission to the catheterization laboratory. ${ }^{19}$ However, the brief time interval between the study drug administration in the ambulance and catheterization laboratory may have limited the potential benefit of pre-hospital ticagrelor administration. Indeed, because of delays in intestinal absorption, a short time from first medical contact to PCI limits the percentage of STEMI patients likely to have fully inhibited platelets at the time of PCI. In fact, the effects of pre-hospital ticagrelor became apparent after $\mathrm{PCI}$, with difference in platelet reactivity and immediate post-PCI reperfusion associated with reductions in ischaemic end points, including ST, over the first 24 hours after PCI and within 30 days. $^{14}$ Whereas the short time to PCI achieved in the ATLANTIC study represents excellent practice, it may not reflect routine practice in a large part of the world. Despite remarkable improvement, ${ }^{48}$ the time to reperfusion therapy for STEMI patients transferred for primary $\mathrm{PCI}$ is often prolonged, with a significant proportion of transferred patients not achieving the guideline-recommended time from diagnosis to 
reperfusion. ${ }^{48,49}$ Patients with a delay between the first medical contact and PCI are those most likely to benefit from an early loading dose, allowing more time for the drug to become biologically active. ${ }^{50}$ Although randomized trials of pre-hospital administration of $\mathrm{P}_{2} \mathrm{Y}_{12}$ inhibitors were not powered to assess the effects on clinical events, it is notable that in a nationwide cohort of STEMI patients transported by physician-staffed emergency medical system ambulances for primary $\mathrm{PCI}$, pre-hospital administration of DAPT was associated with improved survival compared with administration once the patients were admitted to the hospital. ${ }^{51}$ On the other hand, pre-treatment with $\mathrm{P}_{2} \mathrm{Y}_{12}$ receptor antagonists in Sweden was safe but not associated with improved infarct-related artery patency or better clinical outcome than with in-hospital administration. ${ }^{52}$ Beyond the mere comparison of different timings of antiplatelet treatment, the "proof of concept" that early versus delayed $\mathrm{P}_{2} \mathrm{Y}_{12}$ inhibition results in a significantly reduced risk of major adverse cardiac events with no significant difference in terms of bleeding risk is supported by the results of a recent meta-analysis of seven randomized studies that compared early versus delayed $\mathrm{P}^{2} \mathrm{Y}_{12}$ inhibition in 9,648 STEMI patients undergoing PCI. ${ }^{20}$

Administering antiplatelet drugs when the likelihood of STEMI diagnosis is low could lead to an overtreatment of patients who will not ultimately undergo stenting, potentially exposing them to an increased bleeding risk with no potential benefit, or even more deleterious consequence if, for example, urgent surgery is needed for aortic dissection. However, prehospital STEMI diagnosis accuracy is now high, with falsepositive diagnoses now $<5 \%$. As a result, the net potential benefit of pre-hospital $\mathrm{P}_{2} \mathrm{Y}_{12}$ inhibition is considerable.

Potential methods to accelerate the onset of action of the antiplatelet effects of oral $\mathrm{P}_{2} \mathrm{Y}_{12}$ inhibitors include crushing or chewing the tablets. ${ }^{53-55}$ However, the increase in bioavailability of oral $\mathrm{P}_{2} \mathrm{Y}_{12}$ inhibitors with these strategies appears limited. ${ }^{56}$ In the recent FABOLUS-FASTER (facilitation through aggrastat or cangrelor bolus and infusion over prasugrel: a multicenter randomized open-label trial in patients with ST-elevation myocardial infarction referred for primary percutaneous intervention) trial, chewing prasugrel did not result in immediate inhibition of platelet aggregation in the early phase of STEMI, and the results thus support the use of IV drugs to achieve immediate inhibition of platelet aggregation and to bridge the initial gap in platelet inhibition observed with oral $\mathrm{P}_{2} \mathrm{Y}_{12}$ inhibitors.

\section{Intravenous Agents}

\section{Glycoprotein IIb/IIla Inhibitors}

GPIIb/IIIa inhibitors prevent platelet aggregation by blocking the final pathway triggered separately by each of the different platelet activators, namely the binding of fibrinogen and vWF to activated GPIIb/IIIa receptors on the platelet surface. Three agents are currently approved for use: the chimeric monoclonal antibody Fab fragment, abciximab, and the small-molecular GPIIb/IIIa inhibitors, eptifibatide and tirofiban. All three agents are administered intravenously as a bolus, followed by a continuous infusion controlled by a pump and achieve $>80$ to $90 \%$ reduction in platelet aggregation within 10 minutes of the initiation of infusion. The efficacy of GPIIb/IIIa inhibitor administration compared with control therapy has been demonstrated in STEMI managed with PCI although predominately before the common use of the newer oral $\mathrm{P}_{2} \mathrm{Y}_{12}$ receptor inhibitors. ${ }^{57}$ The earlier administration of GPIIb/IIIa inhibitors in AMI may improve pre-PCI perfusion rates, decrease infarct size, and improve microcirculatory function. However, it is challenging to administer these agents rapidly in the pre-hospital setting while transporting patients for PCI. The efficacy and safety of pre-hospital administration of these agents among patients with STEMI has been investigated in several clinical studies.

\section{Abciximab}

Abciximab was the first approved GPIIb/IIIa inhibitor. It was demonstrated to decrease the risk of MACE among patients presenting for both elective and urgent $\mathrm{PCI}$, with or without stenting. ${ }^{58-61}$ Timing of administration was variable in the landmark trials for abciximab, and none of these initial studies administered abciximab in the pre-hospital setting. Data regarding early administration of abciximab in the emergency department show improvement in both clinical and angiographic outcomes and is hypothesized to be due to early recanalization of the infarct-related artery, ${ }^{62-64}$ which is supported by the study by Gold et al demonstrating an increase in coronary artery blood flow within 10 minutes in patients with MI co-treated with aspirin and heparin. ${ }^{13}$ Additionally, data from the ADMIRAL (Abciximab before Direct Angioplasty and Stenting in Myocardial Infarction Regarding Acute and Long-Term Follow-up) trial further reinforced the idea that earlier may be better. The ADMIRAL trial randomized patients presenting for STEMI to either abciximab plus PCI with stenting or placebo plus PCI with stenting. Approximately $26 \%$ of patients included in the study were randomized and treated early in the mobile intensive care unit. Analysis of this subgroup demonstrated that patients who were administered abciximab early were more likely to derive benefit. ${ }^{65}$

Nevertheless, clinical trials evaluating pre-hospital administration of abciximab have had inconsistent results. The REOMOBILE (prehospital versus periprocedural administration of abciximab in STEMI) study was one of the initial trials to evaluate pre-hospital administration of abciximab among patients with STEMI. The trial was small $(n=100)$ and underpowered for its efficacy end points and demonstrated only a trend towards improved ST-segment resolution at 60 to 90 minutes and marginally better angiographic outcomes. ${ }^{66}$ Furthermore, in the MISTRAL (Myocardial Infarction with ST-elevation Treated by Primary Percutaneous Intervention Facilitated by Early Reopro Administration in Alsace) study, pre-hospital administration of abciximab compared with catheterization laboratory administration among patients presenting for STEMI undergoing PCI did not improve either ST-segment resolution or TIMI flow rate after PCI. However, it tended to improve TIMI flow pre-PCI and decreased distal embolization during procedure. ${ }^{67}$ 
Notably, early administration of abciximab was not associated with an increased risk of bleeding. Although smaller studies have demonstrated a higher rate of aborted MI and ST-segment resolution with early pre-hospital administration, ${ }^{68,69}$ the use of abciximab in that setting remains controversial.

Despite abciximab being extensively investigated in the clinical field, it is no longer marketed in the United States, Canada, and most European countries, and this has forced the switch to other GPIIb/IIIa inhibitors, most notably tirofiban.

\section{Eptifibatide}

Eptifibatide was the second GPIIb/IIIa inhibitor approved for clinical use and the first small-molecule GPIIb/IIIa inhibitor. It was shown to reduce the risk of death or non-fatal MI among patients presenting with ACS without persistent ST elevations in the PURSUIT (Platelet Glycoprotein IIb/IIIa in Unstable Angina: Receptor Suppression Using Integrilin Therapy) trial. ${ }^{70}$ In addition, results of the INTAMI trial (Randomized Integrilin in Acute Myocardial Infarction) and the TITAN-TIMI 34 trial (Time to Integrilin Therapy in Acute Myocardial Infarction) provided evidence suggesting that early administration of eptifibatide among STEMI patients may be beneficial. Both trials randomized patients presenting with STEMI to early (emergency department) versus late (cardiac catheterization laboratory) administration of eptifibatide. Patients randomized to early administration of eptifibatide were more likely to have improved epicardial flow by TIMI flow grade and TIMI frame count as well as improved angiographic myocardial perfusion pre-PCI compared with patients who received eptifibatide late. ${ }^{71,72}$ The risk of major bleeding remained comparable in both treatment strategies.

Data on the pre-hospital administration of eptifibatide, however, are limited. The Bochum Feasibility Study was an open-label study that randomized patients with typical angina and concern for ACS to receive standard-of-care therapy versus standard-of-care plus eptifibatide in the ambulance within 6 hours of symptom onset $(n=356)$. Although the primary end point of death, re-infarction, revascularization of target vessels, and major bleeding was lower in the eptifibatide arm (9.6 vs. $11.8 \%$ ), the difference was not statistically significant. ${ }^{73}$

\section{Tirofiban}

Tirofiban is also an IV agent with rapid onset of inhibition of platelet aggregation that is rapidly reversible after discontinuation of the infusion. It has been evaluated as an adjunctive antiplatelet agent among patients presenting with ACS and undergoing PCI or medical management. ${ }^{7-76}$ Among the three commercially available GPIIb/IIla inhibitors, tirofiban has the most consistent data for pre-hospital use. Similar to abciximab and eptifibatide, initial evidence demonstrated that earlier use of tirofiban in STEMI (emergency department setting) was associated with improved ST-segment resolution and target vessel perfusion prior to $\mathrm{PCl} .{ }^{77}$ This suggested that the administration of tirofiban even earlier in the time course of infarction may be of additional benefit.
Most evidence supporting pre-hospital use of tirofiban among patients with STEMI is derived from the On-TIME (Ongoing Tirofiban In Myocardial Infarction Evaluation) 2 trial. On-TIME was a double-blind, multicentre study that randomized STEMI patients who were candidates for PCI to either high-dose bolus pre-hospital tirofiban plus standard of care versus standard of care alone $(n=984)$. The primary study demonstrated significantly better resolution of ST-segment deviation both prior to and post-PCI among patients who received high-dose bolus tirofiban. The composite of death, recurrent MI, urgent target vessel revascularization, or blinded bailout use of tirofiban at 30 days was also significantly lower among patients in the tirofiban arm (32.9 vs. $26.0 \%$; $p=0.02) .{ }^{18}$ Furthermore, additional analyses that combined that pooled data from the open-label phase and the blinded phase of the study demonstrated a significant reduction in MACE (5.8 vs. $8.6 \%, p=0.043$ ), with long-term follow-up showing similar results at 1 year. ${ }^{78}$ Exploratory analyses also showed improvement in initial thrombus burden and initial patency of the infarct-related vessel among patients who were administered tirofiban compared with placebo, ${ }^{79}$ and prehospital tirofiban administration was independently associated with a lower risk of high $\mathrm{N}$-terminal pro-brain natriuretic peptide (NT-proBNP) level after primary $\mathrm{PCI}^{80}$ In the last years, the use of GPI has declined, mainly due to the perception that the ischaemic benefits are counterbalanced by bleeding risks; however, clinical data on GPI bleeding risk may overstate the current experience since it is mainly based on earlier studies that included prolonged post-bolus drug infusion and femoral access site instrumentation. Thus, a high-risk subset of patients may derive particular benefit from early tirofiban treatment in terms of reduced short- and long-term mortality, without a significant increase in bleeding complications. ${ }^{81}$

\section{Intravenous P2Y $_{12}$ Inhibitors: Cangrelor}

Cangrelor is the first and only IV, direct $\mathrm{P}_{2} \mathrm{Y}_{12}$ inhibitor, characterized by rapid onset and offset of action. This makes it ideal for use among patients with STEMI as desired platelet inhibition occurs within minutes of administration, with complete return of platelet function within 60 minutes of discontinuation of the infusion. ${ }^{82}$ Between 2009 and 2013, three pivotal randomized clinical trials from the CHAMPION (Cangrelor Versus Standard Therapy to Achieve Optimal Management of Platelet Inhibition) programme demonstrated that cangrelor administration reduces periprocedural ischaemic complications compared with a clopidogrel loading dose alone. This was, however, associated with an increased risk of GUSTO (Global Use of Strategies to Open Occluded Coronary Arteries) mild bleeding. ${ }^{83}$ In the pooled dataset from these trials, only $11.6 \%$ of patients $(n=2,884)$ enrolled had STEMI and cangrelor was not compared with pre-hospital clopidogrel loading, neither was it compared with more potent and fasteracting P2 $\mathrm{Y}_{12}$ inhibitors. Moreover, transition from cangrelor to the thienopyridines clopidogrel and prasugrel after $\mathrm{PCI}$ is complicated due to a competitive effect between cangrelor and the active metabolites of the oral $\mathrm{P}_{2} \mathrm{Y}_{12}$ inhibitors. ${ }^{84} \mathrm{In}$ STEMI patients, randomized data demonstrated that cangrelor 
may be used as an adjunct to ticagrelor and provides faster and stronger periprocedural platelet inhibition compared with ticagrelor alone ${ }^{85,86}$ However, in the recent FABOLUS-FASTER trial, tirofiban demonstrated superior efficacy than cangrelor on inhibition of platelet aggregation in patients undergoing primary $\mathrm{PCI}$, suggesting that GPI might be preferable to cangrelor to minimize the risk of acute ischaemic complications. ${ }^{87}$ Further studies powered for clinical end points are needed.

\section{Subcutaneous Agents}

\section{Subcutaneous P2Y 12 Inhibitor: Selatogrel}

Selatogrel (ACT-246475), a highly selective and potent 2-phenylpyrimidine-4-carboxamide analogue, ushers in a novel class of reversible P2Y12 receptor antagonists. ${ }^{88}$ The safety and early antiplatelet response to subcutaneous selatogrel has been evaluated in two phase II trials among patients with chronic coronary syndromes (CCS) and patients with AMI scheduled for an invasive strategy ${ }^{89,90}$ (- Table 2). The initial study to evaluate selatogrel was a prospective, multinational, doubleblind, randomized, investigation of 345 patients with CCS receiving conventional background antiplatelet therapy. Patients were randomized to receive subcutaneous selatogrel (8 $\mathrm{mg}[n=114]$ or $16 \mathrm{mg}$ [ $n=115])$ or placebo $(n=116)$ and were classified as responders if the $\mathrm{P}_{2} \mathrm{Y}_{12}$ reaction unit (PRU) measurement utilizing the VerifyNow assay was $<100$ at 30 minutes post-dose and lasted $\geq 3$ hours. At 30 minutes post-selatogrel administration, $89 \%$ of patients were responders to the 8 -mg dose, $90 \%$ to the $16-\mathrm{mg}$ dose, and $16 \%$ to placebo $(p<0.0001)$. PRU remained $<100$ for up to 8 hours for both doses, returning to pre-dose or near pre-dose levels by 24 hours post-dose. Selatogrel achieved additional platelet inhibition in patients already treated with oral $\mathrm{P}_{12} \mathrm{Y}_{12}$ inhibitors. ${ }^{89}$

Selatogrel was also evaluated in another phase II study of 47 patients with ACS (29 of whom had STEMI) along with standard-of-care adjunctive therapy. The response to treatment (defined as $\mathrm{PRU}<100$ ) was evaluated 30 minutes postselatogrel administration ( $8 \mathrm{mg}[n=24]$ or $16 \mathrm{mg}[n=23]$ ). The proportion of responders 30 minutes post-dose was 91 and $96 \%$ with 8 and $16 \mathrm{mg}$, respectively. ${ }^{90}$ In both studies, selatogrel was safe and well tolerated; adverse events were mild in severity, with dyspnoea reported in rates similar to those with ticagrelor. Bleeding events were mostly trivial. Thus, a single subcutaneous injection of selatogrel rapidly inhibits ADP-induced platelet aggregation and may be a promising treatment in the pre-hospital setting and in clinical scenarios where early, rapid, potent, and reversible inhibition of platelet aggregation mediated by ADP is desirable, such as patients presenting with STEMI. Randomized trials are needed to establish the efficacy and safety of subcutaneous selatogrel in such context. A phase III investigation of selatogrel is planned to start in the first half of 2021 as announced by the manufacturer.

\section{Subcutaneous GPIIb/IIla Inhibitor: RUC-4}

RUC-4 differs from current GPIIb/IIIa drugs by its subcutaneous route of administration and its capacity to lock the receptor in its inactive state. ${ }^{91}$ In its phase I trial, the safety of two of RUC- 4 doses $(0.05$ and $0.075 \mathrm{mg} / \mathrm{kg}$ ) were evaluated in 14 healthy volunteers and 28 patients with stable CAD (-Table 2). Patients in both groups achieved more than $80 \%$ platelet inhibition within 15 minutes of administration with a duration of action of $\sim 2$ hours. With regard to RUC-4's safety profile, the majority of adverse events were mild and none led to study drug discontinuation. ${ }^{92}$ An ongoing phase II open-label study (ClinicalTrials.gov Identifier: NCT04284995) is assessing the pharmacodynamic and pharmacokinetic properties of a single subcutaneous injection of RUC-4 in patients with STEMI with planned primary PCI. The simple mode of administration of RUC-4, possibly by an autoinjector, makes it a promising candidate for the management of STEMI at first medical contact, a major unmet need in prehospital care that could potentially improve patient outcomes.

\section{Other Approaches to Platelet Inhibition}

Other novel approaches to platelet inhibition that target other key steps in platelet aggregation are still under investigation. Revacept is an IV platelet collagen receptor inhibitor that acts directly on the target lesion with exposed endovascular collagen, often the primary trigger of platelet aggregation. Given its mechanism of action, Revacept does not affect peripherally circulating platelets, and may potentially lead to lower risk of bleeding. It is currently under investigation in the phase II ISAR-PLASTER (intracoronary stenting and antithrombotic regimen: lesion platelet adhesion as selective target of endovenous revacept) trial among patients with stable coronary disease undergoing elective $\mathrm{PCI} .{ }^{93}$ ARC1779 is an antiplatelet agent that binds the A1 domain of vWF, which acts as a ligand to GP1b receptor on the surface of platelets. Early phase I studies had shown that ARC1779 is well tolerated without an increase in bleeding. ${ }^{94}$ Moreover, the benefits of platelet inhibition may be present beyond their anti-thrombotic effect because activated platelets may contribute to ischaemia/reperfusion (I/R) injury via multiple pathways. ${ }^{95}$ Moreover, platelet inhibition may also diminish $\mathrm{I} / \mathrm{R}$ injury via multiple pathways, including reduced leukocyte recruitment and microparticle formation. ${ }^{95}$ However, the promising results have been shown mainly in pre-clinical setting, and translation into the clinical setting is still under development.

\section{Future Directions}

Novel subcutaneous therapeutic strategies can achieve rapid, high-grade, and rapidly reversible platelet inhibition. These features have the potential to enable new pre-hospital strategies to rapidly achieve patency of the infarct-related vessel prior to PCI. This is likely to translate into decreased infarct size, a reduction in STEMI complications, and overall improvement in morbidity and mortality after MI. Prospective investigations are needed to assess the value of these novel agents, but if they are judged to be safe and efficacious, they will provide important new opportunities in pre-hospital care of ACS. Since they may be self-administered 

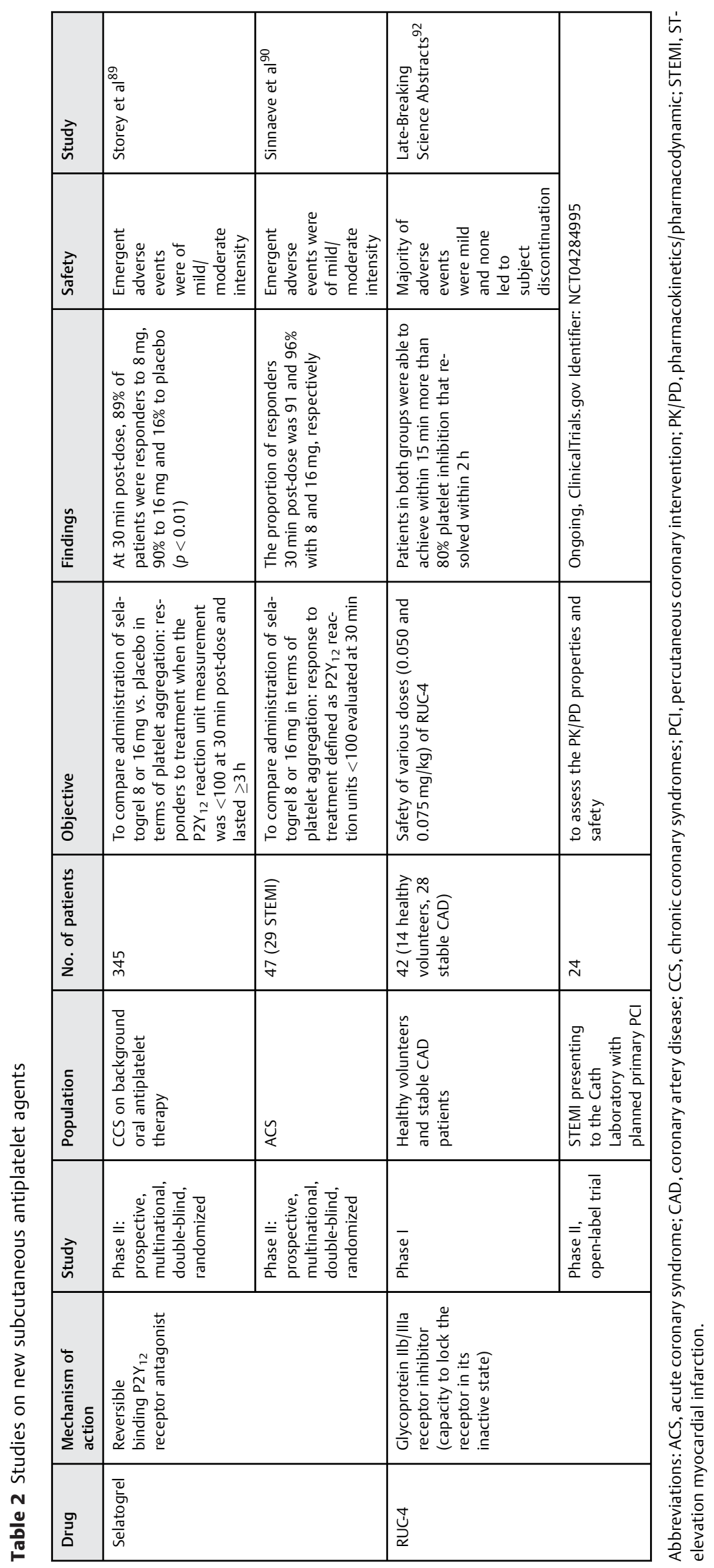

Thrombosis and Haemostasis Vol. 121 No. 12/2021 $\quad$ (c) 2021. Thieme. All rights reserved. 
with auto-injector, or easily administered at first medical contact, they may finally fill the gaps of pre-hospital care which has been identified as the best period to improve outcomes. Nonetheless, in addition to evaluating the agents themselves, understanding the risks and limitations of a strategy of early medical therapy is paramount. Initiating antiplatelet therapy upfront carries the risk of overtreatment, especially when diagnostic uncertainty is present. Other technologies, such as implantable or wearable devices, may complement these new agents by providing more timely recognition of ischaemic events. ${ }^{96}$

\section{Funding}

This work was supported by Grant 19278 from the National Heart, Lung, and Blood Institute and grant UL1 TR001866 from the National Center for Advancing Translational Sciences.

\section{Conflict of Interest}

B.S.C. is an inventor of abciximab and in accord with federal law and the policies of the Research Foundation of the State University of New York, he shares in royalties for the sales of abciximab. He is also an inventor of the VerifyNow assays and receives royalties for the sales of the PRU P2 $\mathrm{Y}_{12}$ cartridge. He is also an inventor of RUC-4 and an equity holder and member of the scientific advisory board of CeleCor Therapeutics, the company that is developing RUC-4. M.G. reports research grant support from Johnson and Johnson, Apple, CSL Behring and Celecor. A.W.J.v.-H. reports unrestricted grants from Medtronic, Abbott, Boehringer Ingelheim, and AstraZeneca. The other authors declare no potential conflict of interest.

\section{References}

1 DeWood MA, Spores J, Notske R, et al. Prevalence of total coronary occlusion during the early hours of transmural myocardial infarction. N Engl J Med 1980;303(16):897-902

2 Popovic B, Agrinier N, Bouchahda N, et al. Coronary embolism among ST-segment-elevation myocardial infarction patients: mechanisms and management. Circ Cardiovasc Interv 2018;11(01):e005587

3 Ibanez B, James S, Agewall S, et al; ESC Scientific Document Group. 2017 ESC Guidelines for the management of acute myocardial infarction in patients presenting with ST-segment elevation: the Task Force for the management of acute myocardial infarction in patients presenting with ST-segment elevation of the European Society of Cardiology (ESC). Eur Heart J 2018;39(02):119-177

4 Valgimigli M, Bueno H, Byrne RA, et al. 2017 ESC focused update on dual antiplatelet therapy in coronary artery disease developed in collaboration with EACTS: the Task Force for dual antiplatelet therapy in coronary artery disease of the European Society of Cardiology (ESC) and of the European Association for CardioThoracic Surgery (EACTS). Eur Heart J 2018;39(03):213-260

5 Furie B, Furie BC. Mechanisms of thrombus formation. N Engl J Med 2008;359(09):938-949

6 Ruggeri ZM. Platelets in atherothrombosis. Nat Med 2002;8(11): 1227-1234

7 Davì G, Patrono C. Platelet activation and atherothrombosis. N Engl J Med 2007;357(24):2482-2494

8 Woodside DG, Liu S, Ginsberg MH. Integrin activation. Thromb Haemost 2001;86(01):316-323
9 Silvain J, Collet J-P, Nagaswami C, et al. Composition of coronary thrombus in acute myocardial infarction. J Am Coll Cardiol 2011; 57(12):1359-1367

10 Fabris E, Arrigoni P, Falco L, et al. Impact of patient delay in a modern real world STEMI network. Am J Emerg Med 2020;38(06): 1195-1198

11 Xu Q Yin J, Si LY. Efficacy and safety of early versus late glycoprotein IIb/IIIa inhibitors for PCI. Int J Cardiol 2013;162(03):210-219

12 De Luca G, Gibson CM, Bellandi F, et al. Early glycoprotein IIb-IIla inhibitors in primary angioplasty (EGYPT) cooperation: an individual patient data meta-analysis. Heart 2008;94(12):1548-1558

13 Gold HK, Garabedian HD, Dinsmore RE, et al. Restoration of coronary flow in myocardial infarction by intravenous chimeric 7E3 antibody without exogenous plasminogen activators. Observations in animals and humans. Circulation 1997;95(07): 1755-1759

14 Montalescot G, van 't Hof AW, Bolognese L, et al; ATLANTIC Investigators. Effect of pre-hospital ticagrelor during the first $24 \mathrm{~h}$ after primary percutaneous coronary intervention in patients with ST-segment elevation myocardial infarction: the ATLANTIC- ${ }^{24}$ analysis. JACC Cardiovasc Interv 2016;9(07): 646-656

15 Smit JJJ, van Werkum JW, ten Berg J, et al; Ongoing Tirofiban in Myocardial Infarction Evaluation (On-TIME) trial investigators. Prehospital triple antiplatelet therapy in patients with acute ST elevation myocardial infarction leads to better platelet aggregation inhibition and clinical outcome than dual antiplatelet therapy. Heart 2010;96(22):1815-1820

16 Jennings LK, Jacoski MV, White MM. The pharmacodynamics of parenteral glycoprotein IIb/IIIa inhibitors. J Interv Cardiol 2002; 15(01):45-60

17 Capranzano P, Angiolillo DJ. Tailoring $\mathrm{P}_{2} \mathrm{Y}_{12}$ inhibiting therapy in elderly patients with myocardial infarction undergoing primary percutaneous coronary intervention. J Am Heart Assoc 2019;8 (18): 014000

18 Van't Hof AW, Ten Berg J, Heestermans T, et al; Ongoing Tirofiban In Myocardial infarction Evaluation (On-TIME) 2 study group. Prehospital initiation of tirofiban in patients with ST-elevation myocardial infarction undergoing primary angioplasty (On-TIME 2): a multicentre, double-blind, randomised controlled trial. Lancet 2008;372(9638):537-546

19 Montalescot G, van 't Hof AW, Lapostolle F, et al; ATLANTIC Investigators. Prehospital ticagrelor in ST-segment elevation myocardial infarction. N Engl J Med 2014;371(11):1016-1027

20 Bellemain-Appaix A, Bégué C, Bhatt DL, et al. The efficacy of early versus delayed $\mathrm{P}_{2} \mathrm{Y}_{12}$ inhibition in percutaneous coronary intervention for ST-elevation myocardial infarction: a systematic review and meta-analysis. EuroIntervention 2018;14(01):78-85

21 Awtry EH, Loscalzo J. Aspirin. Circulation 2000;101(10): 1206-1218

22 RANDOMISED TRIAL OF INTRAVENOUS STREPTOKINASE. Randomised trial of intravenous streptokinase, oral aspirin, both, or neither among 17,187 cases of suspected acute myocardial infarction: ISIS-2. ISIS-2 (Second International Study of Infarct Survival) Collaborative Group. Lancet 1988;2(8607):349-360

23 Sagar KA, Smyth MR. A comparative bioavailability study of different aspirin formulations using on-line multidimensional chromatography. J Pharm Biomed Anal 1999;21(02):383-392

24 O'Gara PT, Kushner FG, Ascheim DD, et al. 2013 ACCF/AHA guideline for the management of ST-elevation myocardial infarction: executive summary: a report of the American College of Cardiology Foundation/American Heart Association Task Force on Practice Guidelines. J Am Coll Cardiol 2013;61(04):485-510

25 Zeymer U, Hohlfeld T, Vom Dahl J, et al. Prospective, randomised trial of the time dependent antiplatelet effects of $500 \mathrm{mg}$ and $250 \mathrm{mg}$ acetylsalicylic acid i. v. and $300 \mathrm{mg}$ p. o. in ACS (ACUTE). Thromb Haemost 2017;117(03):625-635 
26 Meadows TA, Bhatt DL. Clinical aspects of platelet inhibitors and thrombus formation. Circ Res 2007;100(09):1261-1275

27 Capodanno D, Alfonso F, Levine GN, Valgimigli M, Angiolillo DJ. ACC/AHA versus ESC guidelines on dual antiplatelet therapy: JACC guideline comparison. J Am Coll Cardiol 2018;72(23, Pt A):2915-2931

28 Wiviott SD, Braunwald E, McCabe $\mathrm{CH}$, et al; TRITON-TIMI 38 Investigators. Prasugrel versus clopidogrel in patients with acute coronary syndromes. N Engl J Med 2007;357(20):2001-2015

29 Wallentin L, Becker RC, Budaj A, et al; PLATO Investigators. Ticagrelor versus clopidogrel in patients with acute coronary syndromes. N Engl J Med 2009;361(11):1045-1057

30 Claassens DMF, Vos GJA, Bergmeijer TO, et al. A genotype-guided strategy for oral $\mathrm{P}_{2} \mathrm{Y}_{12}$ inhibitors in primary PCI. N Engl J Med 2019;381(17):1621-1631

31 Parodi G, Valenti R, Bellandi B, et al. Comparison of prasugrel and ticagrelor loading doses in ST-segment elevation myocardial infarction patients: RAPID (Rapid Activity of Platelet Inhibitor Drugs) primary PCI study. J Am Coll Cardiol 2013;61(15):1601-1606

32 Motovska Z, Hlinomaz O, Miklik R, et al; PRAGUE-18 Study Group. Prasugrel versus ticagrelor in patients with acute myocardial infarction treated with primary percutaneous coronary intervention: multicenter randomized PRAGUE-18 study. Circulation 2016;134(21):1603-1612

33 Schüpke S, Neumann F-J, Menichelli M, et al; ISAR-REACT 5 Trial Investigators. Ticagrelor or prasugrel in patients with acute coronary syndromes. N Engl J Med 2019;381(16):1524-1534

34 Aytekin A, Ndrepepa G, Neumann F-J, et al. Ticagrelor or prasugrel in patients with ST-segment-elevation myocardial infarction undergoing primary percutaneous coronary intervention. Circulation 2020;142(24):2329-2337

35 Schulz S, Angiolillo DJ, Antoniucci D, et al; Intracoronary Stenting and Antithrombotic Regimen: Rapid Early Action for Coronary Treatment (ISAR-REACT) 5 Trial Investigators. Randomized comparison of ticagrelor versus prasugrel in patients with acute coronary syndrome and planned invasive strategy: design and rationale of the iNtracoronary Stenting and Antithrombotic Regimen-Rapid Early Action for Coronary Treatment (ISAR-REACT) 5 trial. J Cardiovasc Transl Res 2014;7(01):91-100

36 Menichelli M, Neumann F-J, Ndrepepa G, et al. Age- and weightadapted dose of prasugrel versus standard dose of ticagrelor in patients with acute coronary syndromes: results from a randomized trial. Ann Intern Med 2020;173(06):436-444

37 Silvain J, Storey RF, Cayla G, et al. $\mathrm{P}_{2} \mathrm{Y}_{12}$ receptor inhibition and effect of morphine in patients undergoing primary PCI for STsegment elevation myocardial infarction. The PRIVATE-ATLANTIC study. Thromb Haemost 2016;116(02):369-378

38 Hobl E-L, Stimpfl T, Ebner J, et al. Morphine decreases clopidogrel concentrations and effects: a randomized, double-blind, placebo-controlled trial. J Am Coll Cardiol 2014;63(07): 630-635

39 Parodi G, Bellandi B, Xanthopoulou I, et al. Morphine is associated with a delayed activity of oral antiplatelet agents in patients with ST-elevation acute myocardial infarction undergoing primary percutaneous coronary intervention. Circ Cardiovasc Interv 2014;8(01):e001593

40 Zwart B, Yazdani M, Ow KW, et al. Use of glycoprotein IIb/IIIa antagonists to prevent stent thrombosis in morphine-treated patients with ST-elevation myocardial infarction. Platelets 2020;31(02):174-178

41 Lev EI, Kornowski R, Vaknin-Assa H, et al. Effect of clopidogrel pretreatment on angiographic and clinical outcomes in patients undergoing primary percutaneous coronary intervention for STelevation acute myocardial infarction. Am J Cardiol 2008;101(04): 435-439

42 Fefer P, Hod H, Hammerman H, et al. Usefulness of pretreatment with high-dose clopidogrel in patients undergoing primary an- gioplasty for ST-elevation myocardial infarction. Am J Cardiol 2009;104(04):514-518

43 Larson DM, Duval S, Sharkey SS, et al. Clopidogrel pretreatment in ST-elevation myocardial infarction patients transferred for percutaneous coronary intervention. Am Heart J 2010;160(01): 202-207

44 Dörler J, Edlinger M, Alber HF, et al; Austrian Acute PCI Investigators. Clopidogrel pre-treatment is associated with reduced inhospital mortality in primary percutaneous coronary intervention for acute ST-elevation myocardial infarction. Eur Heart J 2011;32(23):2954-2961

45 Bellemain-Appaix A, O'Connor SA, Silvain J, et al; ACTION Group. Association of clopidogrel pretreatment with mortality, cardiovascular events, and major bleeding among patients undergoing percutaneous coronary intervention: a systematic review and meta-analysis. JAMA 2012;308(23):2507-2516

46 Ducci K, Grotti S, Falsini G, et al. Comparison of pre-hospital $600 \mathrm{mg}$ or $900 \mathrm{mg}$ vs. peri-interventional $300 \mathrm{mg}$ clopidogrel in patients with ST-elevation myocardial infarction undergoing primary coronary angioplasty. The Load\&Go randomized trial. Int J Cardiol 2013;168(05):4814-4816

47 Zeymer U, Arntz H-R, Mark B, et al. Efficacy and safety of a high loading dose of clopidogrel administered prehospitally to improve primary percutaneous coronary intervention in acute myocardial infarction: the randomized CIPAMI trial. Clin Res Cardiol 2012;101(04):305-312

48 Krumholz HM, Herrin J, Miller LE, et al. Improvements in door-toballoon time in the United States, 2005 to 2010. Circulation 2011; 124(09):1038-1045

49 Wang TY, Nallamothu BK, Krumholz HM, et al. Association of door-in to door-out time with reperfusion delays and outcomes among patients transferred for primary percutaneous coronary intervention. JAMA 2011;305(24):2540-2547

50 Fabris E, Van't Hof A, Hamm CW, et al. Impact of presentation and transfer delays on complete ST-segment resolution before primary percutaneous coronary intervention: insights from the ATLANTIC trial. EuroIntervention 2017;13(01):69-77

51 Danchin N, Puymirat E, Cayla G, et al; FAST-MI Investigators. Oneyear survival after ST-segment-elevation myocardial infarction in relation with prehospital administration of dual antiplatelet therapy. Circ Cardiovasc Interv 2018;11(09):e007241

52 Redfors B, Dworeck C, Haraldsson I, et al. Pretreatment with P2Y 12 receptor antagonists in ST-elevation myocardial infarction: a report from the Swedish Coronary Angiography and Angioplasty Registry. Eur Heart J 2019;40(15):1202-1210

53 Venetsanos D, Sederholm Lawesson S, Swahn E, Alfredsson J. Chewed ticagrelor tablets provide faster platelet inhibition compared to integral tablets: the inhibition of platelet aggregation after administration of three different ticagrelor formulations (IPAAD-Tica) study, a randomised controlled trial. Thromb Res 2017;149:88-94

54 Alexopoulos D, Barampoutis N, Gkizas V, et al. Crushed versus integral tablets of ticagrelor in ST-segment elevation myocardial infarction patients: a randomized pharmacokinetic/ pharmacodynamic study. Clin Pharmacokinet 2016;55(03): 359-367

55 Rollini F, Franchi F, Hu J, et al. Crushed prasugrel tablets in patients with STEMI undergoing primary percutaneous coronary intervention: the CRUSH study. J Am Coll Cardiol 2016;67(17):1994-2004

56 Vlachojannis GJ, Wilschut JM, Vogel RF, et al. Effect of prehospital crushed prasugrel tablets in patients with ST-segment-elevation myocardial infarction planned for primary percutaneous coronary intervention: the randomized COMPARE CRUSH trial. Circulation 2020;142(24):2316-2328

57 Karathanos A, Lin Y, Dannenberg L, et al. Routine glycoprotein IIb/IIIa inhibitor therapy in ST-segment elevation myocardial infarction: a meta-analysis. Can J Cardiol 2019;35(11):1576-1588 
58 Investigators EEPIC Investigators. Use of a monoclonal antibody directed against the platelet glycoprotein IIb/IIIa receptor in highrisk coronary angioplasty. N Engl J Med 1994;330(14):956-961

59 Investigators EEPILOG Investigators. Platelet glycoprotein IIb/IIIa receptor blockade and low-dose heparin during percutaneous coronary revascularization. N Engl J Med 1997;336(24): 1689-1696

60 Investigators EEPISTENT Investigators. Randomised placebo-controlled and balloon-angioplasty-controlled trial to assess safety of coronary stenting with use of platelet glycoprotein-IIb/IIla blockade. Lancet 1998;352(9122):87-92

61 Randomised placebo-controlled trial of abciximab before and during coronary intervention in refractory unstable angina: the CAPTURE Study. Lancet 1997;349(9063):1429-1435

62 Gabriel HM, Oliveira JA, da Silva PC, da Costa JM, da Cunha JA. Early administration of abciximab bolus in the emergency department improves angiographic outcome after primary PCI as assessed by TIMI frame count: results of the early ReoPro administration in myocardial infarction (ERAMI) trial. Catheter Cardiovasc Interv 2006;68(02):218-224

63 Maioli M, Bellandi F, Leoncini M, Toso A, Dabizzi RP. Randomized early versus late abciximab in acute myocardial infarction treated with primary coronary intervention (RELAx-AMI Trial). J Am Coll Cardiol 2007;49(14):1517-1524

64 Siudak Z, Rakowski T, Dziewierz A, et al. Early abciximab use in ST-elevation myocardial infarction treated with primary percutaneous coronary intervention improves long-term outcome. Data from EUROTRANSFER Registry. Kardiol Pol 2010;68(05): 539-543

65 Montalescot G, Barragan P, Wittenberg O, et al; ADMIRAL Investigators. Abciximab before Direct Angioplasty and Stenting in Myocardial Infarction Regarding Acute and Long-Term Follow-up. Platelet glycoprotein IIb/IIIa inhibition with coronary stenting for acute myocardial infarction. N Engl J Med 2001;344(25): 1895-1903

66 Arntz H-R, Schröder JF, Pels K, et al. Prehospital versus periprocedural administration of abciximab in STEMI: early and late results from the randomised REOMOBILE-study. Eur Heart J 2003;24 (supp 1):268

67 Ohlmann P, Reydel P, Jacquemin L, et al. Prehospital abciximab in ST-segment elevation myocardial infarction: results of the randomized, double-blind MISTRAL study. Circ Cardiovasc Interv 2012;5(01):69-76, S1

68 Hassan AK, Jukema JW, van der Laarse A, et al. Incidence, patient characteristics and predictors of aborted myocardial infarction in patients undergoing primary $\mathrm{PCI}$ : prospective study comparing pre- and in-hospital abciximab pretreatment. EuroIntervention 2009;4(05):662-668

69 Rakowski T, Zalewski J, Legutko J, et al. Early abciximab administration before primary percutaneous coronary intervention improves infarct-related artery patency and left ventricular function in high-risk patients with anterior wall myocardial infarction: a randomized study. Am Heart J 2007;153(03):360-365

70 Platelet Glycoprotein IIb/IIIa in Unstable Angina: Receptor Suppression Using Integrilin Therapy (PURSUIT) Trial Investigators. Inhibition of platelet glycoprotein IIb/IIIa with eptifibatide in patients with acute coronary syndromes. N Engl J Med 1998; 339(07):436-443

71 Zeymer U, Zahn R, Schiele R, et al. Early eptifibatide improves TIMI 3 patency before primary percutaneous coronary intervention for acute ST elevation myocardial infarction: results of the randomized integrilin in acute myocardial infarction (INTAMI) pilot trial. Eur Heart J 2005;26(19):1971-1977

72 Gibson CM, Kirtane AJ, Murphy SA, et al; TIMI Study Group. Early initiation of eptifibatide in the emergency department before primary percutaneous coronary intervention for ST-segment elevation myocardial infarction: results of the Time to Integrilin
Therapy in Acute Myocardial Infarction (TITAN)-TIMI 34 trial. Am Heart J 2006;152(04):668-675

73 Hanefeld C, Sirtl C, Spiecker M, et al. Prehospital therapy with the platelet glycoprotein IIb/IIIa inhibitor eptifibatide in patients with suspected acute coronary syndromes: the Bochum feasibility study. Chest 2004;126(03):935-941

74 Platelet Receptor Inhibition in Ischemic Syndrome Management in Patients Limited by Unstable Signs and Symptoms (PRISM-PLUS) Study Investigators. Inhibition of the platelet glycoprotein IIb/IIIa receptor with tirofiban in unstable angina and non-Q-wave myocardial infarction. N Engl J Med 1998;338(21):1488-1497

75 Platelet Receptor Inhibition in Ischemic Syndrome Management (PRISM) Study Investigators. A comparison of aspirin plus tirofiban with aspirin plus heparin for unstable angina. N Engl J Med 1998;338(21):1498-1505

76 Valgimigli M, Percoco G, Malagutti P, et al; STRATEGY Investigators. Tirofiban and sirolimus-eluting stent vs abciximab and baremetal stent for acute myocardial infarction: a randomized trial. JAMA 2005;293(17):2109-2117

77 Cutlip DE, Ricciardi MJ, Ling FS, et al. Effect of tirofiban before primary angioplasty on initial coronary flow and early ST-segment resolution in patients with acute myocardial infarction. Am J Cardiol 2003;92(08):977-980

78 ten Berg JM, van 't Hof AW, Dill T, et al; On-TIME 2 Study Group. Effect of early, pre-hospital initiation of high bolus dose tirofiban in patients with ST-segment elevation myocardial infarction on short- and long-term clinical outcome. J Am Coll Cardiol 2010;55 (22):2446-2455

79 Hermanides RS, van Werkum JW, Ottervanger JP, et al; Ongoing Tirofiban In Myocardial infarction Evaluation (On-TIME) 2 study group. The effect of pre-hospital glycoprotein IIb-IIla inhibitors on angiographic outcome in STEMI patients who are candidates for primary PCI. Catheter Cardiovasc Interv 2012;79(06):956-964

80 Fabris E, Ottervanger JP, Hermanides RS, et al. Effect of early tirofiban administration on $\mathrm{N}$-terminal pro-B-type natriuretic peptide level in patients treated with primary percutaneous coronary intervention. Catheter Cardiovasc Interv 2019;93(05): E293-E297

81 Fabris E, Kilic S, Schellings DAAM, et al. Long-term mortality and prehospital tirofiban treatment in patients with ST elevation myocardial infarction. Heart 2017;103(19):1515-1520

82 Akers WS, Oh JJ, Oestreich JH, Ferraris S, Wethington M, Steinhubl SR. Pharmacokinetics and pharmacodynamics of a bolus and infusion of cangrelor: a direct, parenteral $\mathrm{P}_{2} \mathrm{Y}_{12}$ receptor antagonist. J Clin Pharmacol 2010;50(01):27-35

83 Steg PG, Bhatt DL, Hamm CW, et al; CHAMPION Investigators. Effect of cangrelor on periprocedural outcomes in percutaneous coronary interventions: a pooled analysis of patient-level data. Lancet 2013;382(9909):1981-1992

84 Steinhubl SR, Oh JJ, Oestreich JH, Ferraris S, Charnigo R, Akers WS. Transitioning patients from cangrelor to clopidogrel: pharmacodynamic evidence of a competitive effect. Thromb Res 2008;121 (04):527-534

85 Franchi F, Rollini F, Rivas A, et al. platelet inhibition with cangrelor and crushed ticagrelor in patients with ST-segment-elevation myocardial infarction undergoing primary percutaneous coronary intervention. Circulation 2019;139(14):1661-1670

86 Alexopoulos D, Pappas C, Sfantou D, et al. Cangrelor in ticagrelorloaded STEMI patients undergoing primary percutaneous coronary intervention. J Am Coll Cardiol 2018;72(14):1750-1751

87 Gargiulo G, Esposito G, Avvedimento M, et al. Cangrelor, tirofiban, and chewed or standard prasugrel regimens in patients with STsegment-elevation myocardial infarction: primary results of the FABOLUS-FASTER trial. Circulation 2020;142(05):441-454

88 Milluzzo RP, Franchina GA, Capodanno D, Angiolillo DJ. Selatogrel, a novel P2Y $\mathrm{Y}_{12}$ inhibitor: a review of the pharmacology and clinical development. Expert Opin Investig Drugs 2020;29(06):537-546 
89 Storey RF, Gurbel PA, Ten Berg J, et al. Pharmacodynamics, pharmacokinetics, and safety of single-dose subcutaneous administration of selatogrel, a novel $\mathrm{P}_{2} \mathrm{Y}_{12}$ receptor antagonist, in patients with chronic coronary syndromes. Eur Heart J 2020;41 (33):3132-3140

90 Sinnaeve P, Fahrni G, Schelfaut D, et al. Subcutaneous selatogrel inhibits platelet aggregation in patients with acute myocardial infarction. J Am Coll Cardiol 2020;75(20):2588-2597

91 Li J, Vootukuri S, Shang Y, et al. RUC-4: a novel $\alpha$ IIb $\beta 3$ antagonist for prehospital therapy of myocardial infarction. Arterioscler Thromb Vasc Biol 2014;34(10):2321-2329

92 Late-Breaking Science Abstracts and Featured Science Abstracts From the American Heart Association's Scientific Sessions 2019 and Late-Breaking Abstracts in Resuscitation Science From the Resuscitation Science Symposium 2019. Circulation 2019;140 (25):e965-e1011
93 Schüpke S, Hein-Rothweiler R, Mayer K, et al; ISAR-PLASTER-Trial Investigators. Revacept, a novel inhibitor of platelet adhesion, in patients undergoing elective PCI-design and rationale of the randomized ISAR-PLASTER trial. Thromb Haemost 2019;119 (09):1539-1545

94 Gilbert JC, DeFeo-Fraulini T, Hutabarat RM, et al. First-in-human evaluation of anti von Willebrand factor therapeutic aptamer ARC1779 in healthy volunteers. Circulation 2007;116(23): 2678-2686

95 Ziegler M, Wang X, Peter K. Platelets in cardiac ischaemia/reperfusion injury: a promising therapeutic target. Cardiovasc Res 2019;115(07):1178-1188

96 Gibson CM, Holmes D, Mikdadi G, et al. Implantable cardiac alert system for early recognition of ST-segment elevation myocardial infarction. J Am Coll Cardiol 2019;73(15): 1919-1927 